\title{
Attached cultivation technology of microalgae for efficient biomass feedstock production
}

\author{
Tianzhong Liu ${ }^{\mathrm{a}, *, 1}$, Junfeng Wang ${ }^{\mathrm{a}, *, 1}$, Qiang Hu ${ }^{\mathrm{b}}$, Pengfei Cheng ${ }^{\mathrm{a}}$, Bei Ji ${ }^{\mathrm{a}}$, Jinli Liu ${ }^{\mathrm{a}}$, Yu Chen ${ }^{\mathrm{a}}$, Wei Zhang ${ }^{\mathrm{a}}$, \\ Xiaoling Chen ${ }^{\mathrm{a}}$, Lin Chen ${ }^{\mathrm{a}}$, Lili Gao ${ }^{\mathrm{a}}$, Chunli Ji ${ }^{\mathrm{a}}$, Hui Wang ${ }^{\mathrm{a}}$ \\ ${ }^{a}$ CAS Key Laboratory of Biofuels, Qingdao Institute of Bioenergy and Bioprocess Technology, Chinese Academy of Sciences, Qingdao, Shandong 266101, PR China \\ ${ }^{\mathrm{b}}$ Laboratory for Algae Research and Biotechnology, Department of Applied Sciences and Mathematics, Arizona State University at the Polytechnic Campus, Mesa, AZ 85212, USA
}

\section{H I G H L I G H T S}

- Attached cultivation + light dilution boosts the biomass production of microalgae.

- An high biomass productivity of $80 \mathrm{~g} \mathrm{~m}^{-2} \mathrm{~d}^{-1}$ for Scenedesmus was obtained outdoors.

- Photosynthetic efficiency of $10.8-17.3 \%$ (visible light) was reached outdoors.

- Potentials of water saving, power cost-effective, contamination control and scale-up.

\section{A R T I C L E I N F O}

\section{Article history:}

Received 17 July 2012

Received in revised form 23 September 2012

Accepted 26 September 2012

Available online 5 October 2012

\section{Keywords:}

Microalgae

Biodiesel

Attached cultivation

Biomass productivity

Photosynthetic efficiency

\begin{abstract}
A B S T R A C T
The potential of microalgae biofuel has not been realized because of low productivity and high costs associated with the current cultivation systems. In this paper, an attached cultivation method was introduced in which microalgae cells grew on the surface of vertical artificial supporting material to form algal film. Multiple of the algal films were assembled in an array fashion to dilute solar irradiation to facilitate high photosynthetic efficiency. Results showed that a broad range of microalgae species can grow with this attached method. A biomass productivity of $50-80 \mathrm{~g} \mathrm{~m}^{-2} \mathrm{~d}^{-1}$ was obtained outdoors for Scenedesmus obliquus, corresponding to the photosynthetic efficiency of 5.2-8.3\% (total solar radiation). This attached method also offers lots of possible advantages over traditional open ponds, such as on water saving, harvesting, contamination controlling and scale-up. The attached cultivation represents a promising technology for economically viable production of microalgae biofuels.
\end{abstract}

@ 2012 Elsevier Ltd. All rights reserved.

\section{Introduction}

The dependence of modern society on fossil fuels since the industrial revolution has been solemnly challenged in recent decades by the resulted crisis of the resource depletion and environment deterioration (Weisz, 2004). Liquid biofuels are considered as sustainable and carbon-neutral alternatives to petroleum-based fuels. Of all the potential feedstock for biofuels, microalgae are believed to be the only possible feedstock that may significantly replace petroleum-based fuels due to its high productivity potential, less competition with food production and less negative impact on the environment when compared with other biomass feedstock options (Chisti, 2007; Hu et al., 2008; Wijffels and Barbosa, 2010).

\footnotetext{
* Corresponding authors. Tel./fax: +86532 80662735.

E-mail addresses: liutz@qibebt.ac.cn (T. Liu), wangjf@qibebt.ac.cn (J. Wang).

1 These authors contributed equally to this work.
}

Although intensive efforts have been made in the past few years on microalgae biofuels research and development (Lam and Lee, 2012; Larkum et al., 2012), no commercial production systems have achieved economic viability (Stephens et al., 2010; Wijffels and Barbosa, 2010) mainly due to the lack of highly efficient and cost-effective large-scale cultivation technology. To date, the prevailing microalgae culturing devices are open ponds and closed photobioreactors of various designs in which microalgae are maintained in liquid suspensions. The highest biomass productivities of ca. $40 \mathrm{~g}$ dry mass $\mathrm{m}^{-2} \mathrm{~d}^{-1}$ were reported from these culture systems (Brennan and Owende, 2010; Mata et al., 2010), which was far less than the theoretical maximum of $120-150 \mathrm{~g} \mathrm{~m}^{-2} \mathrm{~d}^{-1}$, or $12.4 \%$ photosynthetic efficiency to total solar radiation spectrum (for visible light spectrum of solar radiation, the photosynthetic efficiency would be ca. 28\%) (Boyer, 1982; Tredici, 2010; Zhu et al., 2008). The biomass concentration in these conventional open ponds and closed photobioreactors were generally much lower than $10 \mathrm{~g} \mathrm{~L}^{-1}$ (Sastre et al., 2007; Stephens et al., 2010). Demand 
for handling over $99 \%$ water with less than $1 \%$ solids coupled with low biomass productivity makes microalgae mass culture for biofuels neither economically viable nor sustainable from both energy and water supply standpoints (Lehr and Posten, 2009; Walker, 2009). The sustainable supply of low-cost, high volume oil-rich microalgae biomass will be the key to the success of commercialization for the microalgae-derived biofuels (Stephens et al., 2010).

Here, we present a newly attached microalgae cultivation method and a derived cultivation device, called 'attached photobioreactor' (Liu et al., 2010). The core principles of the method and the photobioreactor included: (i) the wet paste of algal cells are attached onto a supporting material to form a thin layer of algal population, which refers to as 'algal film'; (ii) multiple layers of these films are arranged in array fashion to receive the diluted sunlight; (iii) a small volume of culture medium is supplied to the supporting matrix materials to provide the nutrients and moisture to the attached algal cells for growth. This attached cultivation method was evaluated with a number of microalgae strains, and the biomass productivity potential was tested with Scenedesmus obliquus under both indoor and outdoor conditions. According to the results, this attached cultivation method showed a high biomass productivities and photosynthetic efficiencies and possibilities to greatly reduce the water consumption.

\section{Methods}

\subsection{Microalgae strains}

Two fresh water and two marine microalgae species were involved in this research. The fresh water species, i.e. S. obliquus (locally screened in Qingdao, China) and Botryococcus braunii SAG 30.81 (purchased from SAG culture collection, University of Göttingen, Germany), were maintained in BG11 medium (Boussiba and Vonshak, 1991). The marine species Nanochloropsis OZ-1, courtesy of Dr. Feng Chen of The University of Maryland Center for Environmental Science, was maintained in artificial sea water enriched with full strength of BG11 nutrients. The marine species Cylindrotheca fusiformis, courtesy of Prof. Yin Liang of Ocean University of China, was maintained in artificial sea water enriched with $\mathrm{f} / 2$ nutrients (Guillard and Ryther, 1962).

\subsection{Photobioreactors}

Two types of the attached photobioreactors for microalgae were designed and involved in this research.

\subsubsection{Single layer vertical plate attached photobioreactor}

The type 1, which could be called 'single layer vertical plate' system, was used to investigate the growth feasibility of algae cells at attachment (Fig. 1). A $0.2 \times 0.4 \mathrm{~m}$ glass plate ( $3 \mathrm{~mm}$ thickness) was vertically placed in the center of a $0.5 \times 0.3 \times 0.05 \mathrm{~m}$ glass chamber. One surface of the inserted plate, which would be illuminated in the following cultivation, was covered by a layer of filter paper. The algae cells were evenly filtered onto a cellulose acetate/nitrate membrane (pore size $0.45 \mu \mathrm{m}$ ) to form an algal 'disk' with $10 \pm 0.5 \mathrm{~cm}^{2}$ of footprint. The algal 'disk' was then placed onto the filter paper. During the cultivation, the medium was dripped down to the space between the filter paper and glass plate from a perforated nylon tubing which was placed on the top brim of the glass plate, so that the filter paper, cellulose membranes as well as the algae 'disks' were kept wet as the culture medium was soaked in. The flow rate of the culture medium was gently controlled to maintain the well attachment of the algal cells with minimum wash-off.

\subsubsection{The idea of light dilution and multi-plates attached photobioreactor}

Though the type 1 attached cultivation as described above provides the possibility of algal cultivation, when it was applied outdoors, because all of the attached cells directly faced the light without any attenuation, the incident light of ca. $2000 \mu \mathrm{mol}$ photons $\mathrm{m}^{-2} \mathrm{~s}^{-1}$ was too strong to be well handled by the photosystems, and resulted in light inhibition and even photo-bleaching. Thus the high intensity of sunlight must be 'diluted' first to an appropriate level to avoid the light damage. There are at least two basic ways to dilute photons, i.e. (i) whereby expanding the illuminated surface area of the photobioreactor per unit of land area; and (ii) providing incident light in a light/dark cycle rather than in a continuous illumination mode. In this research, we adopted the first strategy in the photobioreactor design.

Type 2 is an experimental prototype photobioreactor for mass scale cultivation. It was applied in this study to testify the biomass productivity potential of the attached cultivation method. This bioreactor was quite similar to type 1 in basic structure except there are multiple (other than single layer) glass plates inserted inside the glass chamber (Fig. 2). Each inserted glass plates together with the attached algal film could be looked as a 'cultivation module' and in the future commercialized equipment, the algal cells should cover the entire surface of this module. However, for the convenience and accuracy of the measurement, we adopted algal 'disk' (Fig. 2D) to estimate the biomass density and biomass productivity in this research. The dimensions of the glass chamber were $w \times h \times l=0.4 \times 0.1 \times 0.3 \mathrm{~m}$ and the inserted glass plate were $0.3 \times 0.1 \mathrm{~m}$. The gap between the adjacent glass plates $\left(w_{\mathrm{p}}\right)$ was changed in $0.02-0.06 \mathrm{~m}$ according to the experimental arrangement. Five faces of the glass chamber were covered by aluminum foil to isolate the un-wanted illumination, while the other face was uncovered and served as the only window to receive light illumination. By this design, the incident light penetrated into the glass chamber was diluted and impinged on the inserted glass plates where the algal cells grow autotrophically.

The light dilution rate $\left(R_{\mathrm{L}}\right)$ for this type 2 photobioreactor was defined as:

$R_{\mathrm{L}}=A_{\mathrm{C}} / A_{\mathrm{L}}$

where the $A_{\mathrm{C}}$ represented the total cultivation surface and $A_{\mathrm{L}}$ represented the light incident area.

\subsubsection{Cultivation conditions}

For both of the two types of the bioreactors, compressed air enriched with $2 \% \mathrm{CO}_{2}(\mathrm{v} / \mathrm{v})$ was aerated into the glass chamber with a speed of $0.1 \mathrm{vvm}$. The temperature inside the glass chamber was kept at $30 \pm 2{ }^{\circ} \mathrm{C}$ during the experiment. The continuous light was provided by cold fluorescence lamp for indoor experiments. For outdoor experiments, the photobioreactors was illuminated with natural solar radiation. The outdoor experiment was carried

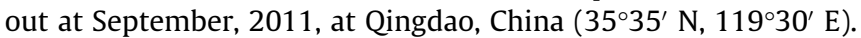

\subsection{Growth analysis}

\subsubsection{For type 1 bioreactor}

The biomass concentration of an algal 'disk' ( $\left.D W, \mathrm{~g} \mathrm{~m}^{-2}\right)$ was measured with gravimetric method. The cells of the algal 'disk' was washed down and re-suspended with de-ionized water and then filtered to pre-weighted $0.45 \mu \mathrm{m} \mathrm{GF/C} \mathrm{filter} \mathrm{membrane}$ (Whatman, England; $D W_{0}$ ). The membrane was oven dried at $105^{\circ} \mathrm{C}$ for $12 \mathrm{~h}$ and then weighted $\left(D W_{1}\right)$. The $D W$ was calculated as:

$D W=\left(D W_{1}-D W_{0}\right) / 0.001$ 


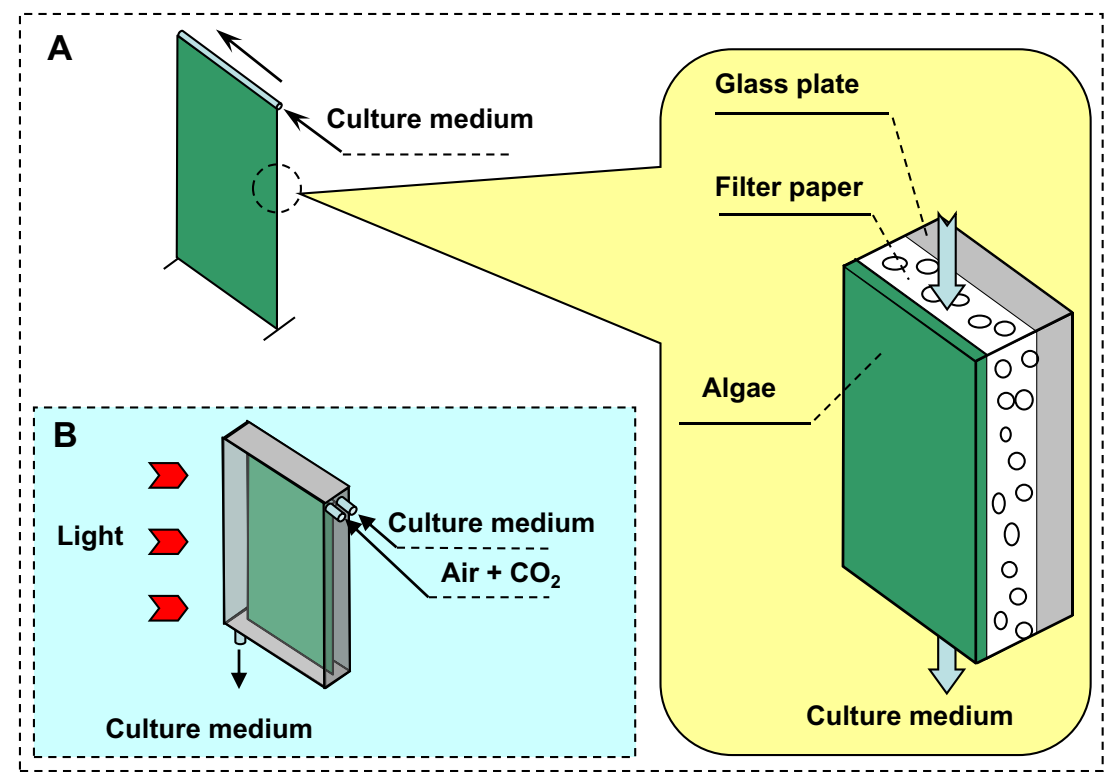

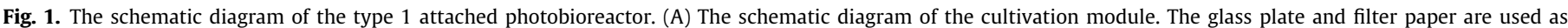

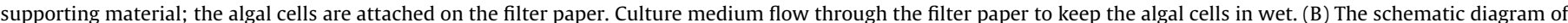

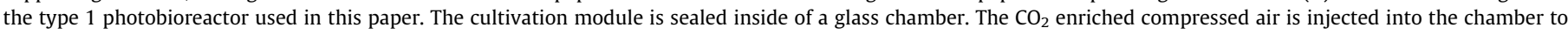
supply the carbon source for the growth of the algal cells. Light impinge on one of the vertical surface of the bioreactor with continuous manner.

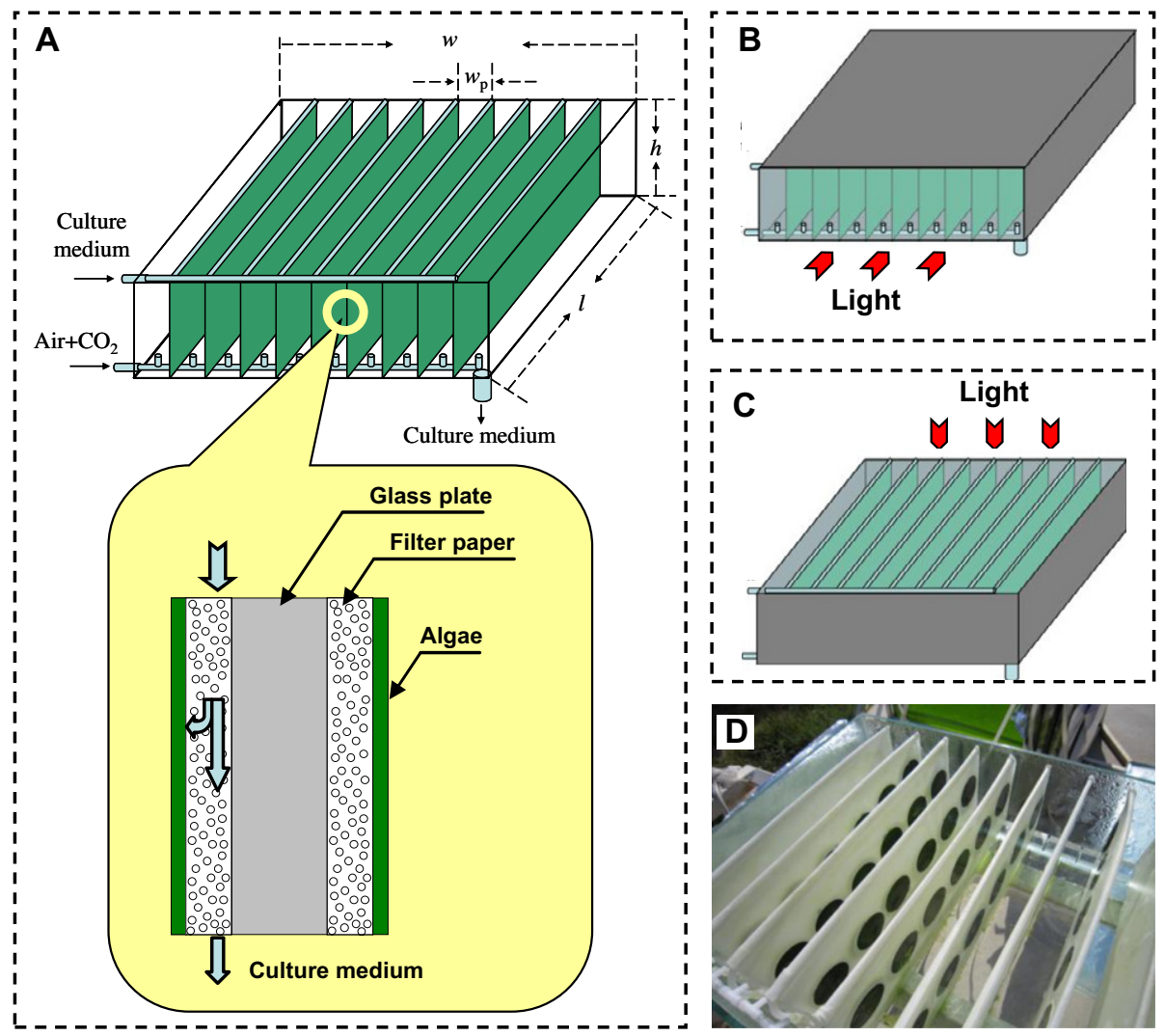

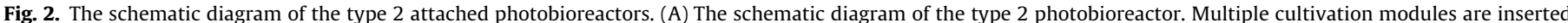

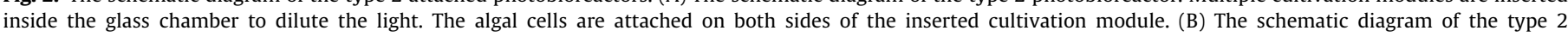

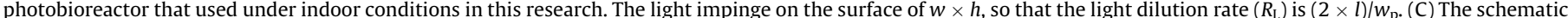

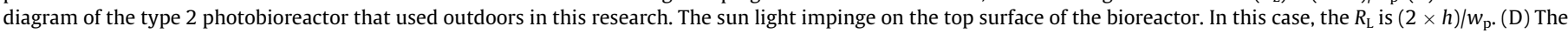
actual photographs of the type 2 photobioreactors during experiments.

where the 0.001 represented the footprint area $\left(\mathrm{m}^{2}\right)$ of attached algal cells. For the experiments with type 1 bioreactor, the biomass concentration of light incident area $\left(D W_{\mathrm{L}}\right)$ was equal to $D W$.

\subsubsection{For type 2 Bioreactor}

For the experiments with type 2 bioreactor the $D W_{\mathrm{L}}$ was calculated as: 
$D W_{\mathrm{L}}=D W_{\mathrm{S}} \times R_{\mathrm{L}}$

where the $D W_{\mathrm{S}}$ and $R_{\mathrm{L}}$ represented the biomass concentration of a single surface of a cultivation module and the light dilution rate, respectively.

For indoor experiments with type 2 bioreactors, six pieces of algal 'disks' were arranged along the light path $(0.3 \mathrm{~m}$ in length; Fig. 2B and D) with the distance of $0.025,0.075,0.125,0.175$, 0.225 and $0.275 \mathrm{~m}$ to the illuminating face (from the center of the attached algal 'disk'). The biomass density of these position points $(y)$ versus distances $(x)$ were plotted and fitted to the equation of

$y=y_{0}+a\left(1-e^{-\mathrm{bx}}\right)$

where the $y_{0}, a$ and $b$ were coefficient of the equation. Integration of the $y$ along the light path $(x=0-0.3 \mathrm{~m})$ was conducted to calculate $D W_{\mathrm{S}}$. The $R_{\mathrm{L}}$ was calculated as $R_{\mathrm{L}}=(2 \times l \times h) /\left(w_{\mathrm{p}} \times h\right)=2 l / w_{\mathrm{p}}=15$, because the $w \times h$ face was illuminated $\left(700 \mu \mathrm{mol}\right.$ photons $\mathrm{m}^{-2} \mathrm{~s}^{-1}$ continuous illumination) and $l$ and $w_{\mathrm{p}}$ were 0.3 and $0.04 \mathrm{~m}$, respectively.

For the outdoor experiments with type 2 bioreactors (Fig. 2C), the biomass density of the algal 'disks', which was placed at the lower part of the cultivation surface (i.e., $0.025 \mathrm{~m}$ from the bottom of the photobioreactor), was taken to represent the average density of the cultivation module $\left(D W_{\mathrm{S}}\right)$. The light intensities at this position were lower than the average value of the entire cultivation surface (data not shown). Accordingly, it is safe to assume that the $D W_{\mathrm{S}}$ was not over estimated. For this experiment, the $R_{\mathrm{L}}$ was calculated as $R_{\mathrm{L}}=(2 \times l \times h) /\left(w_{\mathrm{p}} \times l\right)=2 h / w_{\mathrm{p}}=0.2 / w_{\mathrm{p}}$, because the $w \times l$ face was illuminated and $h$ was $0.1 \mathrm{~m}$. The gap, $w_{\mathrm{p}}$ was set into three different values, i.e., $0.02,0.04$ and $0.06 \mathrm{~m}$ resulted in $R_{\mathrm{L}}$ of $10 \times, 5 \times$ and $3.3 \times$, respectively.

The biomass productivity $\left(\mathrm{g} \mathrm{m}^{-2} \mathrm{~d}^{-1}\right.$ ) was calculated as:

Biomass productivity $=\left(D W_{\mathrm{Ln}}-D W_{\mathrm{L} 0}\right) / n$

where the $D W_{\mathrm{Ln}}$ and $D W_{\mathrm{L} o}$ represented the $D W_{\mathrm{L}}$ of day $n$ and day 0 respectively and ' $n$ ' represented the time of cultivation (days).

The photosynthetic efficiency $(P E)$ was defined as:

$P E=E_{\mathrm{B}} / E_{\mathrm{L}}$

where the $E_{\mathrm{B}}$ and $E_{\mathrm{L}}$ represented the free energy contains in biomass and in light energy, respectively, and calculated according to the following facts: (i) $48 \%$ of the solar radiation is visible light (400$700 \mathrm{~nm}$ ); (ii) One mole of visible photon contains $217 \mathrm{~kJ}$ energy averagely; (iii) One gram of algal biomass under unstressed conditions contains $20 \mathrm{~kJ}$ energy (Boyer, 1982; Tredici, 2010; Zhu et al., 2008).

\subsection{Analysis of total lipid}

The algal biomass of the attached system was washed down and harvested by centrifugation at $10,000 \mathrm{~g}$ for $5 \mathrm{~min}$ and then washed three times with de-ionized water to remove the salt that attached on the surface of the algal cells. The pellet was then lyophilized for lipid analyze by gravimetric methods according to Chen et al. (2012).

\section{Results and discussion}

\subsection{The growth behavior of microalgae under attachment}

In order to assess whether the attached cultivation method would be suitable for microalgae cultivation, the fresh water green microalgae $S$. obliquus and $B$. braunii, the marine unicellular microalgae Nannochloropsis $\mathrm{OZ}-1$, and the marine diatom $C$. fusiformis were cultured in type 1 attached photobioreactor under continu- ous illumination of $100 \mu \mathrm{mol} \mathrm{m}{ }^{-2} \mathrm{~s}^{-1}$ at $25^{\circ} \mathrm{C}$. All of these species exhibited obvious growth in the attached cultivation system (Fig. 3A), indicating this method may be applicable to a broad range of microalgae. The areal biomass density of S. obliquus increased steadily from 10.6 to $83.7 \mathrm{~g} \mathrm{~m}^{-2}$ in 8 days and the thickness of the fresh algal film was increased from 19.5 to $176.9 \mu \mathrm{m}$ (measured by Dektak 150 surface profilometer, Veeco, USA). The SEM images illustrate the changes in the morphology of the cross section of the algal film of the S. obliquus cells (Fig. S1A-C). It was apparent that the cells underneath the algal film were smaller than the ones near and on the surface (Fig. S1B and C), presumably due to the net loss of cell mass by cellular respiration in the dim light or dark. Of these tested species, the $B$. braunii deserved special attention. Many strains of $B$. braunii have the ability to accumulate up to $75 \%$ dwt of hydrocarbons (Banerjee et al., 2002). However, previous attempts of cultivating this organism achieved limited success due to very slow growth rate. According to our results, the biomass productivity of $B$. braunii in traditional glass columns was $0.06 \mathrm{~g} \mathrm{~L}^{-1} \mathrm{~d}^{-1}$, or $2.4 \mathrm{~g} \mathrm{~m}^{-2} \mathrm{~d}^{-1}$ during a 9 day cultivation (Fig. S2), which was similar to that reported by others (Ge et al., 2011). When it was cultivated with the attached system, a biomass productivity of ca. $5.7 \mathrm{~g} \mathrm{~m}^{-2} \mathrm{~d}^{-1}$ was obtained, represented a $150 \%$ increase.

In another experiment, S. obliquus was cultivated on the attached type 1 photobioreactor in the absence of nitrogen, a condition frequently applied to microalgae cultures to induce cellular lipid accumulation (Hu et al., 2008; Rodolfi et al., 2009; Waltz, 2009). As a result, the lipid content was increased from $20.3 \%$ dry weight (dwt) to $47.9 \%$ dwt after 10 days of cultivation (Fig. 3B). The biomass density was increased from 19.4 to $66.3 \mathrm{~g} \mathrm{~m}^{-2}$ in
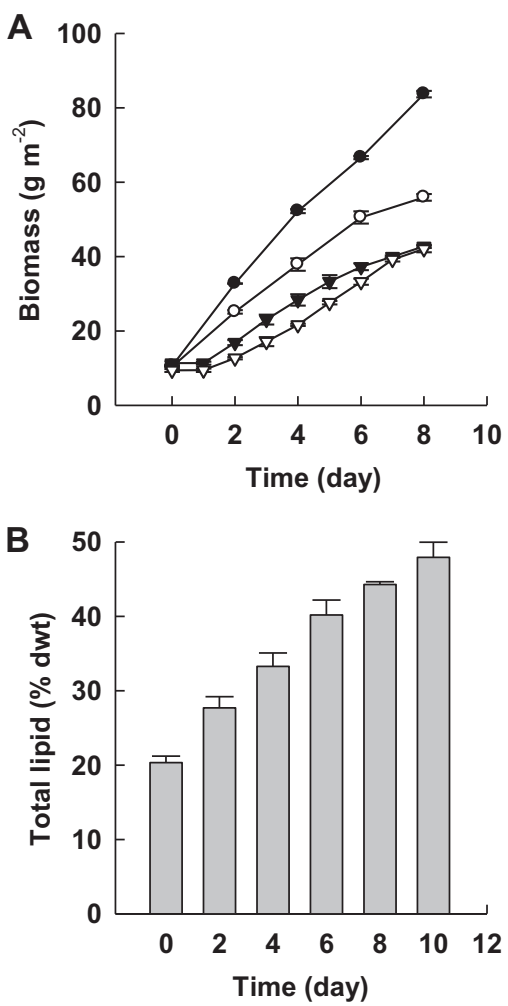

Fig. 3. The growth and lipid accumulation of different microalgal species in the attached photobioreactor. Algal cells were cultivated under indoor conditions with type 1 attached photobioreactor under continuous illumination of $100 \mu \mathrm{mol}$ photons $\mathrm{m}^{-2} \mathrm{~s}^{-1}$. (A) changes in biomass concentration of $S$. obliquus (filled circle), B. braunii SAG 30.81 (open circle), Nanochloropsis OZ-1 (filled triangle) and $C$. fusiformis (open triangle) during the attached cultivation. (B) The changes in total lipid content of S. obliquus during the cultivation with nitrogen free BG11 medium. The data are mean \pm standard deviation of three independent experiments. 
9 days, corresponding to a biomass productivity of $5.2 \mathrm{~g} \mathrm{~m}^{-2} \mathrm{~d}^{-1}$ (Fig. S3).

\subsection{The relationship between light intensity and growth}

The relationship between light intensity and biomass productivity was determined with S. obliquus (Fig. 4). The biomass productivity of attached was approaching to 0 at ca. $10 \mu \mathrm{mol}$ photons $\mathrm{m}^{-2} \mathrm{~s}^{-1}$, which then could be considered as the light compensation point $(L C P)$. In the range of $0-150 \mu \mathrm{mol} \mathrm{m}^{-2} \mathrm{~s}^{-1}$, the biomass productivity increased from -0.7 to ca. $10 \mathrm{~g} \mathrm{~m}^{-2} \mathrm{~d}^{-1}$ with the increasing of the light intensity, however, the increase of biomass productivity slowed down when the light intensity beyond the $150 \mu \mathrm{mol}$ photons $\mathrm{m}^{-2} \mathrm{~s}^{-1}$. These results indicated that the $150 \mu \mathrm{mol}$ photons $\mathrm{m}^{-2} \mathrm{~s}^{-1}$ of light density could be considered as the light saturation point $(L S P)$. The $L C P$ and $L S P$ are critical references for determining the $R_{\mathrm{L}}$. By adjusting the distance between adjacent plates of the type 2 attached photobioreactor, the light intensity received by the algal cells could be higher than $L C P$ but equal or lower than LSP so that to achieve the high biomass productivity as well as high light usage efficiency.

\subsection{Biomass productivity potential of the attached cultivation system}

The growth potential of the attached cultivation of microalgae was firstly evaluated by using type 2 photobioreactor under indoor conditions. The biomass densities at the different distances from the light source during a 9 day cultivation were shown in Fig. 5A. The closer the algal cells toward the light source the more rapidly the cells grew. With the increase of the distance away from the light source, light intensity attenuated and the growth rate decreased in a logarithmic mode. The areal biomass productivity is shown in Fig. 5B. In the first 3 days, the biomass productivity reached $108.1-119.3 \mathrm{~g} \mathrm{~m}^{-2} \mathrm{~d}^{-1}$, which was equal to the photosynthetic efficiency of ca. $18 \%$ (based on visible light spectrum; Tredici, 2010). This level of photosynthetic efficiency was higher than that of the cyanobacterium Spirulina platensis grown in a vertical panel photobioreactor (Hu et al., 1998). During 9 days of cultivation, the average productivity was $70.9 \mathrm{~g} \mathrm{~m}^{-2} \mathrm{~d}^{-1}$ which was equal to the photosynthetic efficiency of ca. $11 \%$ (based on visible light spectrum; Tredici, 2010).

The attached cultivation of $S$. obliquus in type 2 reactor was also conducted outdoors. As shown in Fig. 6, the $R_{\mathrm{L}}$ significantly affected

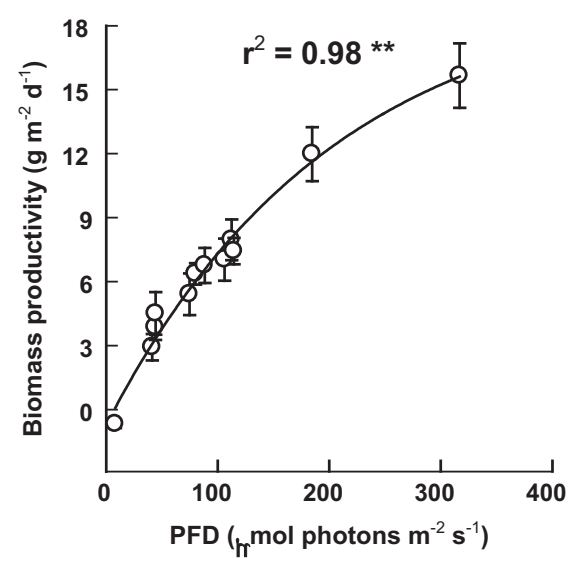

Fig. 4. The relationship between light intensity and biomass productivity of $S$. obliquus in the attached photobioreactor. The algal cells were cultivated for 7 days under indoor conditions with type 1 attached photobioreactor and treated by continuous illumination with different light intensities. The biomass productivity was calculated everyday and then the averaged data of the 7 days are presented in the figure. The data are mean \pm standard deviation of three independent experiments.
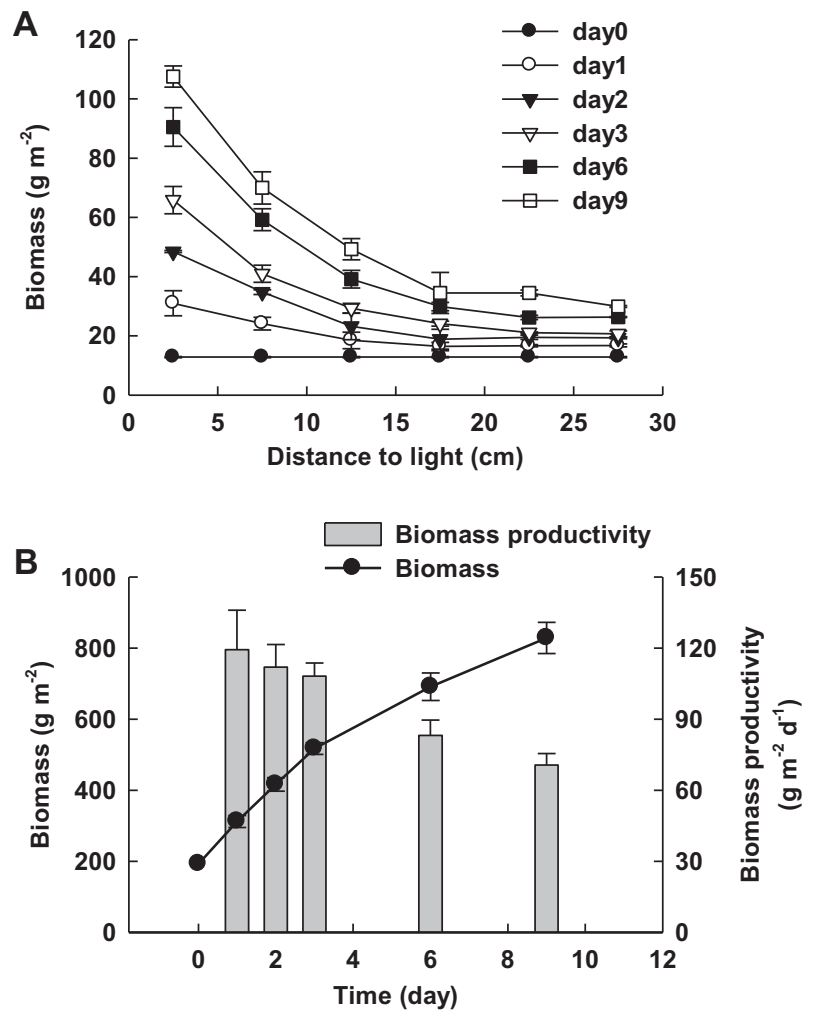

Fig. 5. The growth of $S$. obliquus in the type 2 attached photobioreactor under indoor conditions. (A) The biomass concentrations at the different positions of the cultivation surface from the light source on the different days. The $x$ axis represents the distances of the algal disks from the light source. The light intensities for the algal disks at $2.5,7.5,12.5,17.5,22.5$ and $27.5 \mathrm{~cm}$ were $134.5 \pm 9.6,56.2 \pm 4.4$, $29.3 \pm 2.4,18.7 \pm 1.4,14.2 \pm 0.8$ and $12.8 \pm 0.7 \mu \mathrm{mol}$ photons $\mathrm{m}^{-2} \mathrm{~s}^{-1}$, respectively. (B) The areal biomass concentration and biomass productivity of the type 2 photobioreactor. The data are mean \pm standard deviation of three independent experiments.

the biomass accumulation of the photobioreactor, i.e., the higher $R_{\mathrm{L}}$ value the higher biomass productivity. In the case of $R_{\mathrm{L}}=10 \times$, for example, the biomass productivity was between 50 and $80 \mathrm{~g} \mathrm{~m}^{-2}$ $\mathrm{d}^{-1}$ during a 7 day period of cultivation, which was $400-700 \%$ higher than that obtained from a conventional open pond at the same location during the same period of time (Fig. 6B, Fig. S4A and $\mathrm{B}$ ). This biomass productivity has also exceeded the reported worldwide value of ca. $40 \mathrm{~g} \mathrm{~m}^{-2} \mathrm{~d}^{-1}$ with open pond and various PBRs (Brennan and Owende, 2010; Mata et al., 2010). The daily average of light intensity during this experiment was $492.2 \mu \mathrm{mol}$ photons $\mathrm{m}^{-2} \mathrm{~s}^{-1}$ and accordingly (Tredici, 2010), the biomass productivity of $50-80 \mathrm{~g} \mathrm{~m}^{-2} \mathrm{~d}^{-1}$ was equal to the photosynthetic efficiency of $10.8-17.3 \%$ (visible light), or $5.2-8.3 \%$ (total solar radiation), which were much higher than that of the biofilm photobioreactor introduced by Bayless et al. (2006), Johnson and Wen (2010) and Ozkan et al. (2012). In a 'Performance Summary Report', Pulz depicted a 'record high' outdoor biomass productivity of $174 \mathrm{~g} \mathrm{~m}^{-2} \mathrm{~d}^{-1}$ (maximum) and $98 \mathrm{~g} \mathrm{~m}^{-2} \mathrm{~d}^{-1}$ (average) in Arizona (Pulz, 2007) with a novel '3DMS' cultivation system, however, the photosynthetic efficiency of the involved system is $10.2-21 \%$ (based on visible light spectrum), or $4.8-10.1 \%$ (based on total solar radiation spectrum) (Tredici, 2010), which are similar to that of our prototype bioreactors. The '3DMS' system was not a biofilm or attached cultivation, the algal cells were 'dispersed in an aqueous medium' as in the traditional open ponds and closed photobioreactors. The advantages of our attached cultivation method over the suspended methods will be discussed in the later part.

Notable points are (i) compared with the fall month (September) when this experiment was conducted, the solar radiation is much 

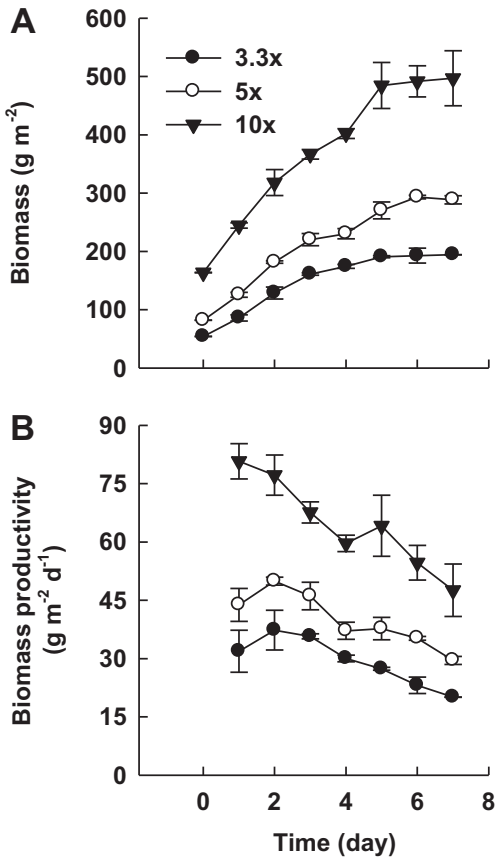

Fig. 6. The growth of $S$. obliquus in the type 2 attached photobioreactor under outdoor conditions. The $3.3 \times, 5 \times, 10 \times$ represent the light dilution rates. The data are mean \pm standard deviation of three independent experiments.

higher in summer months (June, July and August) and so that the biomass productivity of the attached photobioreactor would be further increased. It could also be anticipated that higher biomass productivity than the present level could be reached at those locations with a higher level of photon flux (i.e. tropic desert in Israel, Arizona, Australia, etc.) after optimization of the operation parameters, especially the light dilution rate $R_{\mathrm{L}}$; and (ii) here type 2 bioreactor is only a prototype of attached system, the cultivation surfaces were fixed as a curtain. In the future modified designs, the flashing effect can be introduced into the attached cultivation system by special designs, for example with moving cultivation surface that experience the light-dark cycle in proper frequencies to further increase the biomass productivity as in traditional aqueous-suspended cultivation (Hu et al., 1998; Vejrazka et al., 2011).

The higher biomass productivity and photosynthetic efficiency of the attached cultivation method may be attributable to the improved light availability to algal cells by the multiple surface structure. For conventional open ponds, ca. $10-30 \%$ of the total incident visible radiation was dissipated by the water-air surface through reflection (Goldman, 1979; Kirk, 1994). However, this portion of energy loss could be greatly captured for photosynthesis in the attached cultivation due to the reduced water body. Secondly, with the multiple-plates design, the light distribution fashion was also improved. In conventional ponds or photobioreactors, solar light penetrates only several millimeters of the culture when the cell density was over $1.0 \mathrm{~g} \mathrm{~L}^{-1}$ (Tredici, 2010). However, in the attached system, the light reaches deeply into the bioreactor along the spacing between the adjacent plates, so that the portion of poorly illuminated cell was decreased. In another aspect, the risk of photoinhibition of photosynthesis caused by over-dosed light energy was also reduced by this bioreactor design.

\subsection{The water saving potential and other merits for attached cultivation method}

For conventional open ponds, ca. 200 (80\% of water recycling) -1000 (without water recycling) metric tons of water will be required to produce 1 ton of algal dry mass (Yang et al., 2011). Such huge amount of water consumption is an unaffordable burden for algal feedstock production at large scale. For the attached method, however, algal cells were in pastes status and both nutrients and water environments were maintained by separated flowing medium supplying, thus it provided possibilities to dramatically reduce the water requirement for algal culture. In fact, in this attached cultivation system, all the water in the medium could be divided into three parts: (1) Water in algal paste which is essential for the growth of algal cells. According to our measurements, the water content of the harvested fresh algal paste was $70-80 \%$, indicated that for the first part of water requirement, less than 4 tons of water was adequate to keep the attached algal cells well wetted to produce 1 ton of dry mass. (2) Water for medium circulation. The amount of this part of water depended on the photobioreactor design and operation. Based on our recent experiments, with the aid of a peristaltic pump, an aliquot of $0.1 \mathrm{~L}$ culture medium is enough to wet a cultivation surface of $0.12 \mathrm{~m}^{2}$ and support a biomass productivity of $10 \mathrm{~g} \mathrm{~m}^{-2} \mathrm{~d}^{-1}$ for $S$. obliquus if not considering the evaporation loss (unpublished data). Accordingly, if type 2 attached photobioreactor with outdoor productivity of $50 \mathrm{~g} \mathrm{~m}^{-2} \mathrm{~d}^{-1-}$ was used to produce 1 ton of biomass in 10 days, land area of $2,000 \mathrm{~m}^{2}$ was required, which meant a total cultivation surface of $20,000 \mathrm{~m}^{2}\left(R_{\mathrm{L}}=10\right)$, which then meant ca. 17 tons of water was enough to support the production. (3) Water of evaporation loss during cultivation. The assessment of this part of water is a little complicated, which was not only depended on the bioreactor design, but also mostly dominated by the environmental conditions, such as temperature, wind and humidity. According to Ozkan et al. (2012), ca. $1600 \mathrm{~L}$ of water (>95\% was evaporated!) is required to produce $1 \mathrm{~kg}$ of $B$. braunii biomass with a biofilm photobioreactor, a $45 \%$ decrease compared to open ponds. If the water evaporation was well controlled, the water consumption for mass cultivation with this attached cultivation method could be dramatically decreased, which is help to release the problem of water requirement for the production of microalgae feedstock at large scale.

Other merits of the attached cultivation besides high biomass productivity include: (i) Power cost-effective. Because the microalgae cells attach on the supporting surface in paste form, stirring is not required anymore. Harvesting is easy and cost-effective by scraping down the biomass directly to obtain algal biomass pastes (Ozkan et al., 2012). Furthermore, the low moisture content in the biomass pastes indicated that this attached cultivation methods could provide ready-to-use feedstock, without further dewatering, for other bio-fuel technologies, such as hydrothermal liquefaction (HTL; Vardon et al., 2011); (ii) Easy in contamination control. The contamination by protozoan or bacteria often occur in microalgae mass cultivation (Gonen-Zurgil et al., 1996) and the contamination control for conventional aqueous-suspended cultivation was quite difficult due to the huge water body. For the attached system, however, the contamination would be readily controlled by applying small dose of pesticides or antibiotics; (iii) Easy to scale-up. Due to the weak mechanic strength of transparent materials (such as glass, Plexiglas, plastic membrane etc.) for photobioreactor construction, and the inevitable light attenuation inside the cultures, the single unit of conventional photobioreactor could only be built in slim and thin style with small cultivation volume. As a result, the capital investment for building the conventional cultivation devices in large scale was unaffordable. For the attached cultivation system, these constraints in conventional bioreactor design and scale-up were greatly released. From an engineering aspect, the selection of the supporting materials for algal cell attachment is a critical issue for scaling-up of this cultivation system. The filter membranes used here may not be suitable for mass cultivation because it was expensive and almost un-recyclable. For commercial application, a proper supporting material should be cheap, thin, light weight, durable, water retentive, easy in inoculation and able 
to keep enough algal cells for a new round of re-growth after harvesting.

\section{Conclusions}

In this research, we developed the attached cultivation method and the prototype bioreactors for microalgae. Compared with traditional open ponds, the biomass productivity of the novel designed system was $50-80 \mathrm{gm}^{-2} \mathrm{~d}^{-1}$, or $400-700 \%$ higher and the water consumption was significant saved potentially. This new cultivation provided a promising way to break the bottleneck of feedstock production for microalgae biofuel industry.

\section{Acknowledgements}

This work was supported by the Key Technologies R\&D Program from Ministry of Science and Technology of China (2011BAD14B01), Solar Energy Initiative Plan (KGCX2-EW-309), and International Innovation Partnership Program from Chinese Academy of Sciences.

\section{Appendix A. Supplementary data}

Supplementary data associated with this article can be found, in the online version, at http://dx.doi.org/10.1016/j.biortech.2012.09. 100 .

\section{References}

Banerjee, A., Sharma, R., Chisti, Y., Banerjee, U.C., 2002. Botryococcus braumii: a renewable source of hydrocarbons and other chemicals. Crit. Rev. Biotechnol. 22, 245-279.

Bayless, D.J., Kremer, G., Vis, M., Stuart, B., Shi, L., 2006. Photosynthetic $\mathrm{CO}_{2}$ mitigation using a novel membrane-based photobioreactor. Environ. Eng. Manage. J. 16, 209-215.

Boussiba, S., Vonshak, A., 1991. Astaxanthin accumulation in the green alga Haematococcus pluvialis. Plant Cell Physiol. 32, 1077-1082.

Boyer, J.S., 1982. Plant productivity and environment. Science 218, 443-448.

Brennan, L., Owende, P., 2010. Biofuels from microalgae - a review of technologies for production, processing, and extractions of biofuels and co-products. Renewable Sustainable Energy Rev. 14, 557-577.

Chen, L., Liu, T., Zhang, W., Chen, X., Wang, J., 2012. Biodiesel production from algae oil high in free fatty acids by two-step catalytic conversion. Bioresour. Technol. $111,208-214$.

Chisti, Y., 2007. Biodiesel from microalgae. Biotechnol. Adv. 25, 294-306.

Ge, Y., Liu, J., Tian, G., 2011. Growth characteristics of Botryococcus braumii 765 under high $\mathrm{CO}_{2}$ concentration in photobioreactor. Bioresour. Technol. 102, 130134.

Goldman, J.C., 1979. Outdoor algal mass cultures-II. Photosynthetic yield limitations. Water Res. 13, 119-136.

Gonen-Zurgil, Y., Carmeli-Schwartz, Y., Sukenik, A., 1996. Selective effect of the herbicide DCMU on unicellular algae - a potential tool to maintain a monoalgal culture on Nannochloropsis. J. Appl. Phycol. 8, 415-419.
Guillard, R.R., Ryther, J.H., 1962. Studies of marine planktonic diatoms. I. Cyclotella nana Hustedt and Detonula confervacea (cleve) Gran. Can. J. Microbiol. 8, 229239.

Hu, Q., Sommerfeld, M., Jarvis, E., Ghirardi, M., Posewitz, M., Seibert, M., Darzins, A. 2008. Microalgal triacylglycerols as feedstocks for biofuel production: perspectives and advances. Plant J. 54, 621-639.

Hu, Q., Zarmi, Y., Richmond, A., 1998. Combined effects of light intensity, light-path and culture density on output rate of Spirulina platensis (Cyanobacteria). Eur. J. Phycol. 33, 165-171.

Johnson, M.B., Wen, Z., 2010. Development of an attached microalgal growth system for biofuel production. Biotechnol. Bioprocess Eng. 85, 525-534.

Kirk, J.T.P., 1994. Light and Photosynthesis in Aquatic Ecosystems, second ed. Cambridge University Press, Cambridge.

Lam, M.K., Lee, K.T., 2012. Microalgae biofuels: a critical review of issues, problems and the way forward. Biotechnol. Adv. 30, 673-690.

Larkum, A.W.D., Ross, I.L., Kruse, O., Hankamer, B., 2012. Selection, breeding and engineering of microalgae for bioenergy and biofuel production. Trends Biotechnol. 30, 198-205.

Lehr, F., Posten, C., 2009. Closed photo-bioreactors as tools for biofuel production. Curr. Opin. Biotechnol. 20, 280-285.

Liu, T., Wang, J., Zhang, W., Chen, X., Peng, X., Chen, Y., Chen, L., Gao, L., 2010. A semidry attached microalgae cultivation method that can be applied at industry level. Chinese Pat. 201010250866.X

Mata, T.M., Martins, A.A., Caetano, N.S., 2010. Microalgae for biodiesel production and other applications: a review. Renewable Sustainable Energy Rev. 14, 217 232.

Ozkan, A., Kinney, K., Katz, L., Berberoglu, H., 2012. Reduction of water and energy requirement of algae cultivation using an algae biofilm photobioreactor Bioresour. Technol. 114, 542-548.

Pulz, O., 2007. Performance Summary Report Evaluation of GreenFuel's 3D Matrix Algae Growth Engineering Scale Unit. <http://moritz.botany.ut.ee/ olli/b/ Performance_Summary_Report.pdf $>$.

Rodolfi, L., Zittelli, G.C., Bassi, N., Padovani, G., Biondi, N., Bonini, G., Tredici, M.R. 2009. Microalgae for oil: strain selection, induction of lipid synthesis and outdoor mass cultivation in a low-cost photobioreactor. Biotechnol. Bioeng. $102,100-112$.

Sastre, R.R., Csögör, Z., Perner-Nochta, I., Fleck-Schneider, P., Posten, C., 2007. Scaledown of microalgae cultivations in tubular photo-bioreactors - a conceptual approach. J. Biotechnol. 132, 127-133.

Stephens, E., Ross, I.L., Mussgnug, J.H., Wagner, L.D., Borowitzka, M.A., Posten, C., Kruse, O., Hankamer, B., 2010. Future prospects of microalgal biofuel production systems. Trends Plant Sci. 15, 554-564.

Tredici, M.R., 2010. Photobiology of microalgae mass cultures: understanding the tools for the next green revolution. Biofuels 1, 143-162.

Vardon, D.R., Sharma, B.K., Scott, J., Yu, G., Wang, Z.C., Schideman, L., Zhang, Y.H., Strathmann, T.J., 2011. Chemical properties of biocrude oil from the hydrothermal liquefaction of Spirulina algae, swine manure, and digested anaerobic sludge. Bioresour. Technol. 102, 8295-8303.

Vejrazka, C., Janssen, M., Streefland, M., Wijffels, R.H., 2011. Photosynthetic efficiency of Chlamydomonas reinhardtii in flashing light. Biotechnol. Bioeng. 108, 2905-2913.

Walker, D.A., 2009. Biofuels, facts, fantasy, and feasibility. J. Appl. Phycol. 21, 509517.

Waltz, E., 2009. Biotech's green gold? Nat. Biotechnol. 27, 15-18.

Weisz, P.B., 2004. Basic choices and constraints on long-term energy supplies. Phys. Today $57,47-52$.

Wijffels, R., Barbosa, M., 2010. An outlook on microalgal biofuels. Science 329, $796-$ 799.

Yang, J., Xu, M., Zhang, X., Hu, Q., Sommerfeld, M., Chen, Y., 2011. Life-cycle analysis on biodiesel production from microalgae: water footprint and nutrients balance. Bioresour. Technol. 102, 159-165.

Zhu, X.G., Long, S.P., Ort, D.R., 2008. What is the maxiumum efficiency with which photosynthesis can convert solar energy into biomass? Curr. Opin. Biotechnol. 19, 153-159. 